\title{
The impact of land fragmentation on milk production
}

\author{
J. del Corral, ${ }^{*}$ J. A. Perez, $†$ and D. Roibas $\ddagger^{1}$ \\ *Department of Economics, University of Castilla-La Mancha, Ciudad Real 13071, Spain \\ †Department of Accounting, and \\ ‡Department of Economics, University of Oviedo, Oviedo 33006, Spain
}

\begin{abstract}
The effect of land fragmentation on agriculture has worried policymakers for a long time because it is expected to be a negative effect. Land consolidation policies are frequently implemented to soften the degree of land fragmentation. However, to the authors' knowledge, no study in the dairy sector has empirically analyzed the role of land fragmentation on farm productivity and profits. This study helps to fill this gap in the literature by evaluating the effect of land fragmentation on milk production. To accomplish this, a stochastic frontier production function was estimated. This empirical analysis uses information corresponding to a sample of Spanish dairy farms located in a region where dairy production is by far the most important agricultural product and land is highly fragmented. As policymakers in the region assume that land fragmentation has a negative influence on agricultural production, particularly in dairy production, a land consolidation process was developed. Thereafter, a simulation analysis was carried out to evaluate the increase in profits that could be obtained by reducing land fragmentation. The results show that dairy farms could increase their profits in a range between 9.4 and $14 \%$ by reducing the degree of land fragmentation in a proportion similar to that attained by the land consolidation process that is being carried out in the region.
\end{abstract}

Key words: land fragmentation, technical efficiency, stochastic frontier model

\section{INTRODUCTION}

Land fragmentation (LF), in which a single farm uses several parcels of land, is a common feature in many countries (Blarel et al., 1992; Wan and Cheng, 2001; van Dijk, 2003). This feature is expected to affect farm production negatively for several reasons. Some have to do with forage harvesting and are common to other agricultural practices: (1) fragmentation causes an in-

Received April 26, 2010.

Accepted September 27, 2010.

${ }^{1}$ Corresponding author: droibas@uniovi.es crease in traveling time between fields, which induces both lower labor productivity and higher transport costs for inputs and outputs; (2) said practice reduces the efficiency of machines in relation to that obtainable in large, rectangular fields (Buller and Bruning, 1979); and (3) land is lost when forming plot boundaries and access routes. Other difficulties characteristic to dairy production arise if cows are left to graze and relate to the need to move cattle and milking machinery from one plot to another. However, in this study, the negative effect of land fragmentation in milk production will be mostly due to reasons common to other agricultural production, given that only $15 \%$ of the farms in our sample left the cows to graze and the cows were always returned to the stable at the end of the day.

On the other hand, LF is also expected to have some positive aspects for farmers. Differences in elevation and soil type can be exploited by farmers. Crops at lower elevations mature before than those at higher elevations, and plots with different soil types permit a farmer to produce a more diversified portfolio of crops. Thus, differences in elevation and soil type allow harvests to be synchronized with available family labor thus reducing requirements for hired labor. Additionally, LF is expected to reduce production risk associated with the influence of hailstorms, floods, or fire.

Because the influence of LF on agricultural production is unclear, empirical studies are necessary to assess its effect. Most empirical studies conclude that fragmentation negatively affects agricultural production (Wan and Cheng, 2001; Rahman and Rahman, 2008). However, other studies have not discovered a significant effect of LF on agricultural production (Wu et al., 2005). Therefore, it seems that the effect of LF on agricultural production could depend on the characteristics of the production process analyzed. With regard to the effect of LF on dairy farming, McDowell (1981) indicated that "farm fragmentation is another inhibitor to smallholder participation in dairying. This restricts the practice of grazing and frequently results in low use of crop residues." Hence, LF is assumed to affect milk production negatively. However, no study appears to have analyzed this issue. 
Our empirical analysis uses a sample containing management information for 144 dairy farms over a 9-yr period from 1999 to 2007. These farms are located in Asturias, a region in the northwest of Spain, where dairy farming is the most important agricultural production. In 2007, milk production was responsible for $50 \%$ of agricultural production in Asturias (SADEI, 2009). It is also important to note that land is highly fragmented in the region. The last agrarian census conducted in 1999 showed that the average number of plots per farm was 12.5 (INE, 2010).

The combining of land parcels to ameliorate land fragmentation problems is difficult for dairy farmers due to several factors. The first difficulty is associated with the necessary negotiation among a large number of farmers to interchange plots among each other. Second, any change in plot property or boundaries implies legal costs associated with changes in the Registry of the Property, which is very expensive in Spain. Finally, access routes are public property in Spain and cannot be changed by private citizens; thus, said prohibition seriously limits the potential for land consolidation.

However, as policymakers assume that LF negatively affects agricultural production, two land consolidation mechanisms have been developed in the region. On the one hand, Edict 80/1997 (Boletín Oficial del Principado de Asturias, 1997) establishes the conditions under which farmers can request that the public administration develop a land consolidation process. Thus, the administration decides reorganization of the land and this process avoids negotiations and legal costs and allows the administration to change access routes to the new parcels. On the other hand, the administration itself can promote a local land consolidation process by communicating to the affected farmers that their parcels will be reorganized according to the principles established in the Law 4/1989, Agrarian Regulation and Rural Development (Boletín Oficial Del Principado de Asturias, 1989). Land consolidation processes using both procedures affected 6,722 farms during the period from 1998 to 2007. Specifically, an area of 17,545 ha divided into 50,152 plots was concentrated into 13,949 plots (SADEI, 2009).

The empirical effect of LF on agricultural production has been frequently analyzed by estimating production functions. Some studies have included a LF measure as an additional input in the production function estimation (Wan and Cheng, 2001; Wu et al., 2005). Other studies have analyzed the effect of LF on agriculture using the stochastic production frontier (SPF) approach including some measure of LF as a determinant of the inefficiency component (i.e., the ratio between the actual production and the one attained by fully exploiting the technological potential). Specifically,
Wadud and White (2000) and Rahman and Rahman (2008) analyzed the influence of LF on technical efficiency (TE) for rice farmers in Bangladesh. Carter and Estrin (2001) included a measure of LF to analyze the efficiency determinants in multiple-crop farms in China. This study follows the latter approach that allows identifying the maximum output technologically attainable, and the effect of LF is tested by measuring whether it generates losses in milk production in regard to the maximum potential output. Consequently, the present study implemented an SPF model to analyze the effect of LF in TE among Spanish dairy farms. We carried out a simulation to evaluate the effect of a land consolidation process.

\section{MATERIALS AND METHODS}

\section{Stochastic Frontier Model}

To study the effect of LF on milk production we used a stochastic frontier model (SFM) proposed by Aigner et al. (1977). A stochastic frontier production function may be written as

$$
y_{i t}=f\left(x_{i t}\right) \cdot \exp \left(\varepsilon_{i t}\right) ; \varepsilon_{i t}=v_{i t}-u_{i t},
$$

where $i$ and $t$ denote, respectively, farm and time period, $y$ represents the output quantity, $x$ is a vector of inputs, $f(x)$ represents technology, and $\varepsilon$ is a composed error term. Component $v$ captures statistical noise and other stochastic shocks that enter into the definition of the frontier items such as weather, diseases, and so on, and it is assumed to follow a normal distribution centered at zero. On the other hand, $u$ is a nonnegative term that reflects farm technical inefficiency (i.e., the proportion in which actual output can be augmented to reach the maximum technologically feasible one) and which is assumed to follow a truncated-normal distribution.

An SFM can be used not only to estimate the frontier production parameters, but also to analyze the determinants of the inefficiency component. Early approaches to this technique estimated an SFM and subsequently the estimated efficiencies were regressed against some exogenous variables in a second-stage regression. However, serious econometric problems were associated with this 2-stage formulation. Wang and Schmidt (2002) demonstrate than if in the first step "the dependence of inefficiency on $\mathrm{z}$ is ignored, the estimated firm-level efficiencies are spuriously under-dispersed. As a result the second-step regression understates the effect of $\mathrm{z}$ on efficiency levels" (Wang and Schmidt, 2002; p. 130). To avoid these problems several authors developed the 
so-called one-stage models (e.g., Huang and Liu, 1994; Battese and Coelli, 1995; Caudill et al., 1995) in which the inefficiency effects are estimated simultaneously with the technological parameters. To accomplish the objective of analyzing the effect of LF on farm TE, the Battese and Coelli (1995) model will be used. This model can be expressed as

$$
y_{i t}=f\left(x_{i t}\right)+v_{i t}-u_{i t} ; u_{i t}=z_{i t} \delta+W_{i t} \text {, }
$$

where $z$ is a vector of farm-management variables that explain inefficiency, $\delta$ is a vector of parameters to be estimated, and $W$ is defined by a normal distribution truncated at $-z \delta$ with zero mean and variance $\sigma_{u}^{2}$. It is also assumed that $v$ and $u$ are independent. This model allows the efficiency distribution to depend on both kinds of variables: time-invariant and time-variant for each farm, which is the case in the study at hand. The parameters of the stochastic frontier and the model for the technical inefficiency effects are simultaneously estimated by maximum likelihood.

The SFM depicted in equation [1] allowed measurement of an index for TE, which is defined as the ratio of the observed output $(y)$ and maximum feasible output $\left(y^{*}\right)$ :

$$
\mathrm{TE}_{i t}=\frac{y_{i t}}{y_{i t} *}=\frac{f\left(x_{i t}\right) \cdot \exp \left(v_{i t}-u_{i t}\right)}{f\left(x_{i t}\right) \cdot \exp \left(v_{i t}\right)}=\exp \left(-u_{i t}\right) .
$$

Because $y$ is always lower than or equal to $y^{*}$, the TE index is bounded between 0 and 1; TE achieves its upper bound when a dairy farm is producing the maximum technologically feasible output (i.e., $y=y^{*}$ ), given the input quantities.

\section{Empirical Model}

In this study, the production function was modeled using a flexible functional form. This form is based on a second-order Taylor expansion, which allows for a good approximation to the true, and unknown, production function (Chambers, 1988). The translog functional form (Christensen et al., 1973) was chosen for this study. This functional form is frequently used to model dairy production (e.g., Alvarez and Arias, 2004; Lawson et al., 2004; Roibás and Alvarez, 2010).

The dependent variable is the production of milk. Five inputs are considered: (1) labor, which includes family labor and hired labor and is measured in fulltime equivalents; that is, a full-time adult employee with $1,920 \mathrm{~h}$ per year (40 h/wk for $48 \mathrm{wk}$ in a year);
(2) cows, defined as the number of adult cows in the herd; (3) concentrates, measured in kilograms; (4) forage expenses, defined as forage purchases plus the costs of seeds, fertilizers, machinery, fuel, and land; and (5) animal expenses, defined as livestock supplies, and breeding and veterinary expenses. All the monetary variables are expressed in 2007 US dollars (the original data in 2007 Euros were converted to US\$ using the exchange rate of December 31, 2007: $\$ 1.4603=1 €$ ). Additionally, time dummy variables were introduced to check for factors that affect all farms in the same way but which may vary over time, such as weather variations and technical change (1999 is the base year).

The variables included as inefficiency determinants were a measure of LF and other variables related with farm practices and characteristics. Land fragmentation can be measured in several ways, including the Simpson index (Simpson, 1949; used by Blarel et al., 1992 and Wu et al., 2005 among others), the number of plots (Wan and Cheng, 2001; Di Falco et al., 2010), and the average plot size (Nguyen et al., 1996; Wadud and White, 2000). The use of the Simpson index is not possible given that our data did not contain information about the plot's area (only the farmland surface and number of plots is known). Thus, in this study LF was measured by the number of plots. The square of the number of plots is also included because of the expectation that the influence of an additional plot diminishes with the total number of plots (i.e., the influence of an additional plot in milk production is expected to be different for a farm with 2 plots than for a farm with 25 plots).

Other variables included as inefficiency determinants were concentrates/cow (Hallam and Machado, 1996; Kompas and Che, 2006; Cabrera et al., 2010); land (defined as the total number of hectares used on the farm); family labor (the ratio of family labor to total labor; Cabrera et al., 2010); equipment per cow (equipment including machinery amortization plus fuel and electricity expenses; Hallam and Machado, 1996); owned land (the ratio of owned land to total land, which can be considered as a measure of land dispersion because owned land is expected to be closer to the farm than rented land); pasture (Cabrera et al., 2010), a dummy variable equal to 1 for farms that left the cows to graze; housing (Cabrera et al., 2010), a dummy variable equal to 1 for farms that use freestall housing; milking system (Cabrera et al., 2010), a dummy variable that takes on the value of 1 if the milking system is parlor and 0 if otherwise; and (to consider different weather and ground conditions) zone, a dummy variable equal to 1 for farms located in a coastal county.

Thus, the model to be estimated can be expressed as 
Table 1. Number of farms available in each year from 1999 to 2007

\begin{tabular}{lccccccccc}
\hline Item & 1999 & 2000 & 2001 & 2002 & 2003 & 2004 & 2005 & 2006 & 2007 \\
\hline Farms (n) & 106 & 104 & 116 & 122 & 127 & 132 & 136 & 144 & 143 \\
\hline
\end{tabular}

$$
\begin{gathered}
\ln y_{i t}=\beta_{0}+\sum_{j=1}^{5} \beta_{j} \ln x_{j i t}+\frac{1}{2} \sum_{j=1}^{5} \sum_{k=1}^{5} \beta_{j k} \ln x_{j i t} \ln x_{k i t} \\
+\sum_{t=2000}^{2007} \beta_{t} D_{t}+v_{i t}-u_{i t} \\
u_{i t} \sim T N\left(\delta_{0}+\sum_{l=1}^{11} \delta_{l} z_{l i t}, \sigma_{u}\right)
\end{gathered}
$$

from 1999 to 2007. This record-keeping program collects information about 9 Dairy Farmers Management Associations located in Asturias. These associations are funded by the regional government and their main objective is to provide management advisement to their associated farmers. To collect the data necessary for the advisement function, each farm is visited monthly by a technician. The monthly information is combined with annual inventories to create an annual report of each farm. Data from these annual reports have been used in other studies regarding dairy farm production (Alvarez et al., 2008; Alvarez and del Corral, 2010; Roibás and Alvarez, 2010). Furthermore, in 2008, a survey was conducted among the farmers associated with the Dairy Farmers Management Associations to determine the number of plots that each farm had in 2007.

The analysis was carried out assuming that if a farm does not change the number of hectares, then the number of plots remains constant. That is, if for some farm the number of hectares in 2004 was different from that in 2007, then observations corresponding to 2004 and previous years were excluded from the data. This is the main reason for the increasing number of observations

\begin{tabular}{|c|c|c|c|c|}
\hline Variable & Mean & $\mathrm{CV}$ & Minimum & Maximum \\
\hline Milk (L) & 311,346 & 0.67 & 31,665 & $1,202,702$ \\
\hline Labor (full-time equivalents) & 1.76 & 0.45 & 0.37 & 8.73 \\
\hline Cows (n) & 40.12 & 0.51 & 8.50 & 149.25 \\
\hline Concentrates (kg) & 149,593 & 0.73 & 12,147 & 789,215 \\
\hline Forage expenses $\left(\$^{1}\right)$ & 39,177 & 0.81 & 952 & 258,394 \\
\hline Animal expenses $(\$)$ & 20,162 & 0.78 & 1,043 & 217,325 \\
\hline Land (ha) & 18.67 & 0.57 & 2 & 82 \\
\hline Plots (n) & 13.55 & 0.61 & 2 & 46 \\
\hline Concentrates/cow (ratio) & 3,488 & 0.30 & 994 & 6,878 \\
\hline Family labor $(\text { ratio })^{2}$ & 0.95 & 0.18 & 0 & 1 \\
\hline Equipment/cow & 268 & 0.51 & 17 & 843 \\
\hline Owned land (ratio) ${ }^{3}$ & 0.57 & 0.51 & 0 & 1 \\
\hline Zone (dummy) & 0.28 & 1.61 & 0 & 1 \\
\hline Pasture (dummy) ${ }^{5}$ & 0.15 & 2.39 & 0 & 1 \\
\hline Housing (dummy) & 0.47 & 0.93 & 0 & 1 \\
\hline Milking system (dummy) ${ }^{7}$ & 0.48 & 0.96 & 0 & 1 \\
\hline
\end{tabular}
per year (see Table 1). From what is observed in the

Table 2. Descriptive statistics for sample dairy farms from 1999 to 2007

${ }^{1}$ The original data in $2007 €$ were converted to US $\$$ using the exchange rate of December 31, 2007: $\$ 1.4603$ $=1 €$.

${ }^{2}$ Family labor $=$ family labor $/$ total labor.

${ }^{3}$ Owned land $=$ own land $/$ total land.

${ }^{4}$ Coast $=1$.

${ }^{5}$ Use of pasture $=1$.

${ }^{6}$ Freestall housing $=1$.

${ }^{7}$ Parlor $=1$. 
Table 3. Yearly variable profits per cow (2007 US\$ per cow) on farms using fewer and more than 11 plots (sample median) from 1999 to 2007

\begin{tabular}{lccccccccc}
\hline Plots (n) & 1999 & 2000 & 2001 & 2002 & 2003 & 2004 & 2005 & 2006 & 2007 \\
\hline$<11$ & 1,749 & 1,796 & 2,039 & 1,431 & 1,548 & 1,650 & 1,655 & 1,339 & 1,638 \\
$>11$ & 1,649 & 1,669 & 1,993 & 1,516 & 1,497 & 1,428 & 1,541 & 1,320 & 1,571 \\
\hline
\end{tabular}

database, this is not a strong assumption. This selection process led to an unbalanced panel that contained 1,130 observations.

Table 2 provides a descriptive summary of the variables used in this study. The dairy farms in the sample were highly specialized, with more than $90 \%$ of farm income coming from dairy sales. The average farm in the sample was larger than the average Spanish farm (26 cows; Eurostat, 2010) but similar to the average farm in some of the main milk producers countries in

Table 4. Production frontier estimates

\begin{tabular}{|c|c|c|}
\hline Variable & Coefficient & $\mathrm{SD}$ \\
\hline \multicolumn{3}{|l|}{ Frontier } \\
\hline Constant & $12.546^{* * *}$ & 0.031 \\
\hline Labor (full-time equivalents) & $0.056^{* * *}$ & 0.015 \\
\hline Cows (n) & $0.683^{* * *}$ & 0.045 \\
\hline Concentrates $(\mathrm{kg})$ & $0.081^{* *}$ & 0.039 \\
\hline Forage expenses $(\$)$ & $0.146^{* * *}$ & 0.013 \\
\hline Animal expenses (\$) & $0.080^{* * *}$ & 0.011 \\
\hline Labor $\times$ labor & $-0.110^{*}$ & 0.060 \\
\hline Cows $\times$ cows & $-0.923^{* * *}$ & 0.177 \\
\hline Concentrates $\times$ concentrates & 0.001 & 0.078 \\
\hline Forage expenses $\times$ forage expenses & 0.023 & 0.025 \\
\hline Animal expenses $\times$ animal expenses & -0.034 & 0.030 \\
\hline Labor $\times$ cows & $0.234^{* * *}$ & 0.076 \\
\hline Labor $\times$ concentrates & 0.005 & 0.040 \\
\hline Labor $\times$ forage expenses & $-0.065^{* * *}$ & 0.025 \\
\hline Labor $\times$ animal expenses & $-0.046^{*}$ & 0.028 \\
\hline Cows $\times$ concentrates & 0.123 & 0.087 \\
\hline Cows $\times$ forage expenses & $0.230 * * *$ & 0.053 \\
\hline Cows $\times$ animal expenses & $0.183^{* * *}$ & 0.056 \\
\hline Concentrates $\times$ forage expenses & $-0.153^{* * *}$ & 0.031 \\
\hline Concentrates $\times$ animal expenses & $-0.062^{*}$ & 0.034 \\
\hline Forage expenses $\times$ animal expenses & $0.057^{* * *}$ & 0.022 \\
\hline $\mathrm{T}_{2000}$ (dummy) & 0.021 & 0.016 \\
\hline $\mathrm{T}_{2001}$ (dummy) & $0.035^{* *}$ & 0.016 \\
\hline $\mathrm{T}_{2002}$ (dummy) & $0.056 * * *$ & 0.016 \\
\hline $\mathrm{T}_{2003}$ (dummy) & $0.062^{* * *}$ & 0.016 \\
\hline $\mathrm{T}_{2004}$ (dummy) & $0.075^{* * *}$ & 0.016 \\
\hline $\mathrm{T}_{2005}$ (dummy) & $0.121^{* * *}$ & 0.017 \\
\hline $\mathrm{T}_{2006}$ (dummy) & $0.143^{* * *}$ & 0.018 \\
\hline $\mathrm{T}_{2007}$ (dummy) & $0.136^{* * *}$ & 0.018 \\
\hline \multicolumn{3}{|l|}{ Inefficiency model } \\
\hline Constant & $0.2946 * * *$ & 0.0839 \\
\hline Plots $(n)$ & $0.0130 * * *$ & 0.0026 \\
\hline Plots $\times$ plots & $-0.0002^{* * *}$ & 0.0001 \\
\hline Land (ha) & $0.0014^{* *}$ & 0.0006 \\
\hline Concentrates/cow (ratio) & $-0.0001^{* * *}$ & 0.0000 \\
\hline Family labor (ratio) & $0.0940^{*}$ & 0.0498 \\
\hline Equipment/cow (ratio) & 0.0001 & 0.0001 \\
\hline Owned land/total land (ratio) & $-0.0385^{* *}$ & 0.0184 \\
\hline Zone $(\text { dummy })^{1}$ & $0.0480^{* * *}$ & 0.0129 \\
\hline Pasture (dummy) $)^{2}$ & -0.0096 & 0.0147 \\
\hline Housing (dummy) ${ }^{3}$ & $-0.0685^{* * *}$ & 0.0178 \\
\hline Milking system (dummy) & $0.0444^{* *}$ & 0.0192 \\
\hline$\sigma_{u}$ & 0.0925 & \\
\hline$\sigma_{v}$ & 0.0877 & \\
\hline Log-likelihood & 825.46 & \\
\hline
\end{tabular}

${ }^{1}$ Coast $=1$.

${ }^{2}$ Use of pasture $=1$.

${ }^{3}$ Freestall housing $=1$.

${ }^{4}$ Parlor $=1$

${ }^{*} P<0.10$; ${ }^{* *} P<0.05$; *** $P<0.01$. 
Table 5. Milk and concentrates prices (2007 US\$) from 1999 to 2007

\begin{tabular}{lcccccccccc}
\hline Price & 1999 & 2000 & 2001 & 2002 & 2003 & 2004 & 2005 & 2006 & 2007 \\
\hline Milk $(\$ / \mathrm{L})$ & 0.70 & 0.67 & 0.72 & 0.61 & 0.58 & 0.57 & 0.53 & 0.48 & 0.54 \\
Concentrates $(\$ / \mathrm{kg})$ & 0.50 & 0.45 & 0.42 & 0.42 & 0.41 & 0.42 & 0.41 & 0.38 & 0.35 \\
\hline
\end{tabular}

Europe such as France or Germany (40 cows; Eurostat, 2010). Differences among farms are important because the standard deviation of milk production was $67 \%$ of the mean production. Finally, it is worth noting that land was highly fragmented because the average number of plots per farm was approximately 14 .

In a preliminary analysis, the farms were classified into 2 groups depending on whether the number of plots was smaller or larger than the sample median (11 plots). Variable profits (milk sales minus feeding costs and animal expenses) per cow were calculated for each farm. Table 3 shows the average variable profits per cow for each group of farms in each sample period. In every year except 2002, farms using fewer than 11 plots achieved larger variable profits per cow than farms using more than 11 plots. On average, farms using fewer than 11 plots earned $\$ 73$ more per cow than farms using more than 11 plots. However, this preliminary analysis does not allow us to conclude that the number of plots is the unique cause of the observed economic advantage of the first group. Other differences among the farms can also contribute to these differences in profits. The estimation of the empirical model proposed in equations [4] and [5] allowed us to isolate the influence of land fragmentation on farm profits.

\section{RESULTS AND DISCUSSION}

Following a common practice when estimating a translog functional form (Cuesta, 2000; Alvarez et al., 2008; Moreira and Bravo-Ureta, 2010), the explanatory variables were divided by their geometric mean, so that the first-order coefficients could be interpreted as output elasticities; that is, the percentage change in production when the corresponding input increases by $1 \%$ for a farm characterized by an input endowment equal to the sample geometric mean.

Table 4 presents the estimated production frontier and the inefficiency determinants. All output elasticities were positive and statistically significant; that is, all inputs had a positive effect on milk production, as expected. The input with the highest output elasticity was cows (0.68): a $1 \%$ increase in the number of cows resulted in an estimated increase of $0.68 \%$ in milk produced. The other output elasticities were labor (0.06), concentrates (0.08), forage expenses (0.15), and animal expenses (0.08). Time dummies showed that during the sample period, productivity increased by around 13 to $14 \%$. Time dummy coefficients include technical change as well as any other not observed variables that are time-specific such as weather. Roibás and Alvarez (2010) used a similar database to show that the main source of technical change was genetic progress. Scale elasticity (i.e., the sum of all output elasticities) was 1.05, which is different from $1(P<0.01)$ showing some slight increasing returns to scale. That is, if all the inputs increased in the same proportion, then milk production would increase in a slightly larger proportion. This result is in line with previous studies using a similar data set (see Alvarez and del Corral, 2010).

In regard to the focus of this study, the results suggest that technical inefficiency increased with the number of plots $(P<0.01)$ but this influence was attenuated by the number of plots given that the coefficient of quadratic term was negative $(P<0.01)$. Moreover, concentrates/cow increased TE $(P<0.01)$. The same outcome was found in Cabrera et al. (2010) for Wisconsin dairy farms, in Hallam and Machado (1996) for Portuguese dairy farms, and in Kompas and Che (2006) for Australian dairy farms. This result shows that intensive farms tend to be more efficient than extensive ones (Alvarez and del Corral, 2010). The variables land and family labor had positive coefficients $(P<0.1)$, indicating that the more land a farm has and the greater

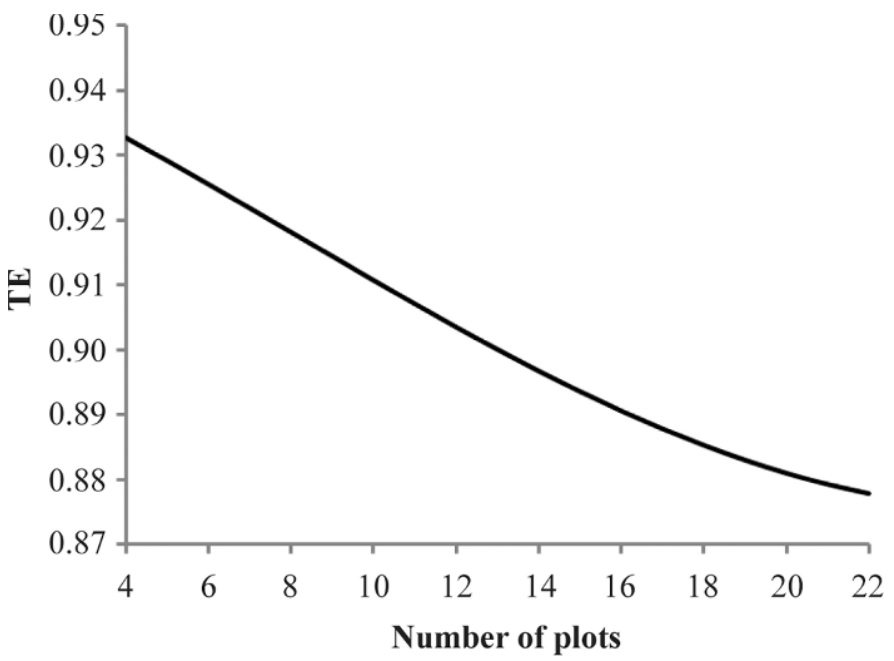

Figure 1. Expected technical efficiency (TE) for the average arm. 
Table 6. Average farm variable profits (2007 US\$) depending on the number of plots from 1999 to 2007

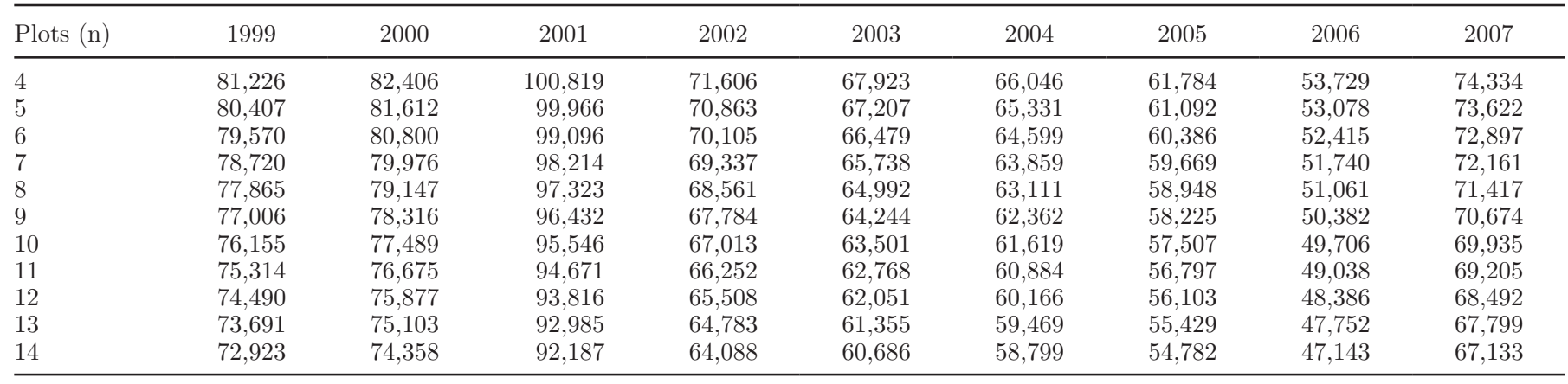

the percentage of family labor a farm uses, the less technically efficient the farm is. Cuesta (2000) found a negative elasticity of labor for Spanish dairy farms and argues "farms in the sample are family run farms and the labor variable could be reflecting a disguised unemployment problem." It is clear that this problem is not associated with farms using hired labor, but farms using only family labor can, at least partially, continue suffering from this problem. As expected, TE increased with the ratio of owned land, showing that the closer the parcels are to the farm, the more technically efficient the farm is $(P<0.05)$. The coefficient of the zone variable was positive $(P<0.01)$, which means that conditions for dairy farming are better in the interior than on the coast. Freestall farms were found to be more efficient than non-freestall farms. On the other hand, parlor farms were found to be less efficient than stanchion farms $(P<0.05)$. In our sample, most freestall farms $(>90 \%)$ used a parlor milking system and most non-freestall farms used a stanchion milking system; however, according to our results, the most efficient farms were freestall farms using a stanchion milking system. Last, the variables equipment/cow and pasture were found to be nonsignificant. Related to the pasture variable, a similar result was found in Cabrera et al. (2010).

To evaluate the influence of LF on milk production, a simulation analysis was carried out. The expected TE score was calculated for the average farm, which corresponded to the average values on inputs and efficiency determinants in Table 2 (for efficiency determinants defined as dummy variables we chose the most efficient configuration - a freestall farm that used a stanchion milking system and that was located in the interior zone of Asturias), depending on the number of plots. The $u_{i t}$ expectation $[E(u)]$ was calculated using the following expression (Stevenson, 1980):

$$
E(u)=\delta_{0}+\sum_{l=1}^{11} \delta_{l} z_{i t}+\sigma_{u} \frac{\varphi\left(-\left(\delta_{0}+\sum_{l=1}^{11} \delta_{l} z_{i t}\right) / \sigma_{u}\right)}{1-\Phi\left(-\left(\delta_{0}+\sum_{l=1}^{11} \delta_{l} z_{i t}\right) / \sigma_{u}\right)},
$$

where $\varphi$ represents the standard normal density function and $\Phi$ is the standard normal distribution function. Figure 1 represents the expected TE score for the average farm for a quantity of plots between 4 and 22 (which roughly correspond to adding and subtracting 1 $\mathrm{SD}$ to/from the sample average). A proportional reduction in the number of plots similar to that achieved by the land consolidation process carried out in Asturias implies a reduction in the number of plots from 14, which roughly corresponds to the sample average, to 4 . This reduction in the number of plots implied an increase in the expected TE index for the average farm from 89.6 to $93.3 \%$ (see Bravo-Ureta et al., 2007 for technical efficiency in dairy farming studies).

To evaluate the economic impact of an increase in TE based on a reduction in the number of plots, the variable profits attained were simulated for the average farm during the sample period. Variable profits are defined by the difference between the income generated by selling milk and the variable costs, including animal expenses and feeding costs (forage expenses plus concentrates cost). Income due to milk sales were

Table 7. Percentage increase in variable profits reducing plots from 14 to 4

\begin{tabular}{lrrrrrrrrrr}
\hline Variable & 1999 & 2000 & 2001 & 2002 & 2003 & 2004 & 2005 & 2006 & 2007 \\
\hline Percentage increase & 11.4 & 10.8 & 9.4 & 11.7 & 11.9 & 12.3 & 12.8 & 14.0 & 10.7 \\
\hline
\end{tabular}


calculated using the average milk price on the sample for each year. The expected output was calculated by entering the input endowment corresponding to the average farm in the estimated function. To calculate the cost of concentrates, the average sample concentrate price by year was used. Table 5 shows yearly milk and concentrates prices expressed in 2007 dollars per liter and dollars per kilogram, respectively. Therefore, yearly differences in profits are caused by differences in milk and concentrate prices and on yearly productivity differences associated with time dummies. Differences in profits due to the number of plots were associated only with changes in TE. Table 6 shows the variable profits simulation.

Table 7 shows the percentage variable profit increase caused by a reduction in the number of plots from 14 to 4 . Therefore, a reduction in the number of plots similar to that carried out by the consolidation process in Asturias allows for, on average, an $11.7 \%$ increase in profits. The minimum increase $(9.4 \%)$ corresponded to the most profitable year (2001), and the maximum increase (14\%) took place in 2006, which was the least profitable year. Therefore, the proportional impact of LF increased with low values of milk prices. Thus, as milk prices are expected to remain low, the relative impact of LF is expected to be greater in the future.

\section{CONCLUSIONS}

Land fragmentation is expected to have both positive and negative effects on agricultural production. Thus, the net effect of LF on milk production has to be empirically established. This objective was accomplished by using a sample of Spanish dairy farms located in a region where dairy farming is responsible for $50 \%$ of the total agricultural production, which is characterized by a high degree of LF, and where a land consolidation process is being carried out. An SPF approach was used to assess the influence of LF on milk production. The results show that LF had, as expected, a significant negative influence on TE. According to the estimation, reducing the number of plots on the average farm from 14 to 4 allowed for an increase in profits of $11.7 \%$ on average. It is worth noting that the impact of this decrease in the number of plots increases when milk price is low. Thus, the analysis carried out in this study shows that a land consolidation policy could be a useful tool to improve farm profitability, especially in a situation where milk prices are expected to remain low in the future.

\section{ACKNOWLEDGMENTS}

The authors gratefully acknowledge the financial support provided by FICYT (grant PC06-28, Asturias,
Spain). The authors also thank the Grupos de Gestion de Explotaciones Lecheras Asturianos (Oviedo, Asturias, Spain) and the Consejeria de Medio Rural y Pesca of the Principado de Asturias (Oviedo, Asturias, Spain) for providing us with the data. Finally, we thank Daniel Solis (Division of Agribusiness, Florida A\&M University, Tallahassee, FL) who provided several useful suggestions. REFERENCES

\section{REFERENCES}

Aigner, D., K. Lovell, and P. Schmidt. 1977. Formulation and estimation of stochastic frontier production function models. J. Econom. $6: 21-37$.

Alvarez, A., and C. Arias. 2004. Technical efficiency and farm size: A conditional analysis. Agric. Econ. 30:241-250.

Alvarez, A., and J. del Corral. 2010. Identifying different technologies using a latent class model: Extensive versus intensive dairy farms. Eur. Rev. Agric. Econ. 37:231-250.

Alvarez, A., J. del Corral, D. Solis, and J. A. Perez. 2008. Does intensification improve the economic efficiency of dairy farms? J. Dairy Sci. 91:3693-3698.

Battese, G., and T. Coelli. 1995. A model for technical inefficiency effects in a stochastic frontier production function for panel data. Empir. Econ. 20:325-332.

Blarel, B., P. Hazell, F. Place, and J. Quiggin. 1992. The economics of farm fragmentation: Evidence from Ghana and Rwanda. World Bank Econ. Rev. 6:233-254.

Bravo-Ureta, B., D. Solís, V. H. Moreira, J. Maripani, A. Thiam, and T. Rivas. 2007. Technical efficiency in farming: A meta-regression analysis. J. Prod. Anal. 27:57-72.

Buller, O., and G. Bruning. 1979. Management effects of spatially dispersed land tracts: a simulation analysis. Western J. Agric. Econ. 4:129-142.

Cabrera, V. E., D. Solís, and J. del Corral. 2010. Determinants of technical efficiency among dairy farms in Wisconsin. J. Dairy Sci. 93:387-393.

Carter, C. A., and A. J. Estrin. 2001. Market reforms versus structural reforms in rural China. J. Comp. Econ. 29:527-541.

Caudill, S. B., J. M. Ford, and D. M. Gropper. 1995. Frontier estimation and firm-specific inefficiency measures in the presence of heteroscedasticity. J. Bus. Econ. Stat. 13:105-111.

Chambers, R. G. 1988. Applied Production Analysis: A Dual Approach. Cambridge University Press, Cambridge, UK.

Christensen, L., D. Jorgenson, and L. Lau. 1973. Transcendental logarithmic production frontiers. Rev. Econ. Stat. 55:28-45.

Cuesta, R. A. 2000. A production model with firm-specific temporal variation in technical inefficiency with application to Spanish dairy farms. J. Prod. Anal. 13:139-158.

Boletín Oficial Del Principado de Asturias. 1989. Ley 4/89, de 21 de julio, de ordenación agraria y desarrollo rural. Boletin Oficial del Principado de Asturias 193:3733-3746.

Boletín Oficial Del Principado de Asturias. 1997. Decreto 80/97, de 18 de dicienzbre, por el que se establece el procedimiento de ln concentración parcelaria de carácter privado. Boletin Oficial del Principado de Asturias 6:101-103.

Di Falco, S., I. Penov, A. Aleksiev, and T. van Rensburg. 2010. Agrobiodiversity, farm profits and land fragmentation: Evidence from Bulgaria. Land Use Policy 27:763-771.

Eurostat. 2010. Structure of agricultural holdings by region, main indicators. Accessed April 20, 2010. http://epp.eurostat.ec.europa.eu/ portal/page/portal/agriculture/data/database.

Hallam, D., and F. Machado. 1996. Efficiency analysis with panel data: A study of Portuguese dairy farms. Eur. Rev. Agric. Econ. 23:79-93.

Huang, C., and J. Liu. 1994. Estimation of a non-neutral stochastic frontier production function. J. Prod. Anal. 5:171-180.

INE. 2010. Censo Agrario 1999. http://www.ine.es/ 
Kompas, T., and T. Che. 2006. Technology choice and efficiency on Australian dairy farms. Aust. J. Agric. Resour. Econ. 50:65-83.

Lawson, L. G., J. Bruun, T. Coelli, J. F. Agger, and M. Lund. 2004. Relationships of efficiency to reproductive disorders in Danish milk production: A stochastic frontier analysis. J. Dairy Sci. $87: 212-224$.

McDowell, R. 1981. Limitations for dairy production in developing countries. J. Dairy Sci. 64:2463-2475.

Moreira, V., and B. Bravo-Ureta. 2010. Technical efficiency and metatechnology ratios for dairy farms in three southern cone countries: A stochastic meta-frontier model. J. Prod. Anal. 33:33-45.

Nguyen, T., E. Cheng, and C. Findlay. 1996. Land fragmentation and farm productivity in China in the 1990's. China Econ. Rev. 7:169-180.

Rahman, S., and M. Rahman. 2008. Impact of land fragmentation and resource ownership on productivity and efficiency: The case of rice producers in Bangladesh. Land Use Policy 26:95-103.

Roibas, D., and A. Alvarez. 2010. The impact of genetic progress on the profits of dairy farmers. J. Dairy Sci. 93:4366-4373.

SADEI. 2009. La agricultura asturiana. Cuentas económicas 2006. Referencias Estadísticas 2007. Servicio de Publicaciones del Principado de Asturias, Oviedo, Spain.
Simpson, E. H. 1949. Measurement of diversity. Nature 163:688.

Stevenson, R. E. 1980. Likelihood functions for generalised stochastic frontier estimation. J. Econom. 13:57-66.

van Dijk, T. 2003. Scenarios of Central European land fragmentation. Land Use Policy 20:149-158.

Wadud, A., and B. White. 2000. Farm household efficiency in Bangladesh: A comparison of stochastic frontier and DEA methods. Appl. Econ. 32:1665-1673.

Wan, G. H., and E. Cheng. 2001. Effects of land fragmentation and returns to scale in the Chinese farming sector. Appl. Econ. 33:183194.

Wang, H., and P. Schmidt. 2002. One-step and two-step estimation of the effects of exogenous variables on technical efficiency levels. J. Prod. Anal. 18:129-144.

Wu, Z., M. Liu, and J. Davis. 2005. Land consolidation and productivity in Chinese household crop production. China Econ. Rev. $16: 28-49$. 